\section{A CRITICAL APPRAISAL OF PEXELIZUMAB TREATMENT IN PATIENTS UNDERGOING CORONARY ARTERY BYPASS GRAFTING}

\section{To the Editor:}

We appreciate the recent article by Smith and colleagues, ${ }^{1}$ in which they reported that pexelizumab was associated with a nonsignificant reduction in the primary postoperative composite end point in patients enrolled in the Pexelizumab for Reduction of Infarction and Mortality in Coronary Artery Bypass Graft Surgery (PRIMOCABG) II trial. An exploratory analysis of the combined PRIMO-CABG I and II data sets, however, showed a mortality benefit for high-risk surgical patients. ${ }^{1,2}$ Obviously, the authors hypothesized a moderational model regarding pexelizumab treatment, which is only effective in high-risk surgical patients. Recently, we have established a mediational model regarding the pexelizumab treatment in patients with severe coronary artery disease undergoing primary coronary revascularization on the basis of the results of the experiment by Røger and colleagues $^{3}$ and the mathematic estimates of the relative risks of death. ${ }^{4}$ Our hypothesis is that pexelizumab may cause platelet aggregation, leading to postprocedural myocardial infarction and death. On the other hand, pexelizumab would reduce myocardial reperfusion injury after revascularization. The cardioprotective

\footnotetext{
The Editor welcomes submissions for possible publication in the Letters to the Editor section that consist of commentary on an article published in the Journal or other relevant issues. Authors should: - Include no more than 500 words of text, three authors, and five references. - Type with double-spacing - See http://jtcs.ctsnetjournals.org/misc/ifora.shtm for detailed submission instructions. $\bullet$ Submit the letter electronically via jtcvs.editorialmanager.com Letters commenting on an article published in the JTCVS will be considered if they are received within 6 weeks of the time the article was published. Authors of the article being commented on will be given an opportunity of offer a timely response ( 2 weeks) to the letter. Authors of letters will be notified that the letter has been received. Unpublished letters cannot be returned.
}

effect of pexelizumab is remarkably dependent on the condition of adequate antithrombotic therapy. ${ }^{5}$

As we know, more high-risk surgical patients were enrolled in PRIMO-CABG II than in PRIMOCABG I, and the moderational model failed to show better effectiveness of pexelizumab in PRIMO-CABG II than in PRIMO-CABG I. ${ }^{5}$ We explain the results yielded by the mediational model by positing that heparinization during coronary artery bypass grafting may be a pivotal confounder between these 2 trials. Clinically, the activated clotting time should be maintained at longer than 450 seconds for patients undergoing coronary artery bypass grafting with cardiopulmonary bypass circuits, or longer than 250 seconds for those undergoing operation with heparin-bonded cardiopulmonary bypass circuits. ${ }^{5}$ Thus to counteract the platelet aggregation effect of pexelizumab without adequate antiplatelet therapy during coronary artery bypass grafting may require a large amount of heparin to achieve longer activated clotting time, aiming to suppress the thrombin activity. There were, however, no data regarding the use of heparin and the target activated clotting time during coronary artery bypass grafting in either PRIMO-CABG I or PRIMO-CABG II. $^{5}$ Of note, both PRIMO-CABG I and PRIMO-CABG II were conducted in North America and Western Europe, with the former trial being held at 205 hospitals from January 2002 to February 2003 and the latter trial being held at 249 hospitals from June 2004 to July 2005. In time, heparin-bonded cardiopulmonary bypass circuits may replace traditional cardiopulmonary bypass circuits to become the main option for patients undergoing coronary artery bypass grafting in the Western countries, because their safety has been demonstrated by reductions in the amount of perioperative heparin use and in the number of postoperative bleeding events. Accordingly, there may be a bias between PRIMO-
CABG I and PRIMO-CABG II if the unbalanced use of heparin-bonded cardiopulmonary bypass circuits is taken into account.

In our opinion, a retrospective survey regarding the types of cardiopulmonary bypass circuits used in PRIMO-CABG I and PRIMOCABG II is suggested. It would be useful to estimate the odds ratios for the primary composite end point with different cardiopulmonary bypass circuits in a multiple regression analysis.

Gen-Min Lin, MD
Yi-Hwei Li, ScD, PhD
Chih-Lu Han, MD,PhD
${ }^{a}$ Department of Medicine
Hualien Armed Forces General
Hospital
Hualien, Taiwan
${ }^{b}$ Department of Public Health
Tzu-Chi University
Hualien, Taiwan
Taipei Veterans General Hospital
Taipei, Taiwan

\section{Reference}

1. Smith PK, Shernan SK, Chen JC, Carrier M, Verrier ED, Adams PX, et al. Effects of C5 complement inhibitor pexelizumab on outcome in high-risk coronary artery bypass grafting: combined results from the PRIMO-CABG I and II trials. J Thorac Cardiovasc Surg. Epub 2010 Sep 27.

2. Verrier ED, Shernan SK, Taylor KM, Van de Werf F, Newman MF, Chen JC, et al. Terminal complement blockade with pexelizumab during coronary artery bypass graft surgery requiring cardiopulmonary bypass: a randomized trial. JAMA. 2004;291:2319-27

3. Røger M, Høgåsen K, Holme PA, Halstensen TS, Mollnes TE, Hovig T. The Fluid-phase SC5b-9 Terminal Complement Complex Binds to the GPIIb/ IIIa Complex of Thrombin-stimulated Human Blood Platelets Inhibiting Platelet Aggregation. Platelet. 1995;6:160-8.

4. Lin GM, Chu KM, Han CL. Pexelizumab may be hazardous to those with ST-segment elevation myocardial infarction undergoing primary percutaneous interventions without using glycoprotein IIb-IIIa inhibitors. Int $J$ Cardiol. 2010;146: 280-2.

5. Lin GM, Li YH, Wen SH, Chen SY, Chu KM, Han CL. Predictors, moderators and mediators for the effectiveness of pexelizumab treatment in patients undergoing primary coronary revascularization. Int J Cardiol. 2011;147:340-1.

doi:10.1016/j.jtcvs.2011.03.030 